OPEN ACCESS

Edited by:

Pedro Piedras,

Universidad de Córdoba, Spain

Reviewed by:

Jing Zhang,

Nanjing Agricultural University, China

Mohammad Nauman Khan,

Huazhong Agricultural University,

China

*Correspondence:

$\mathrm{HaO} \mathrm{Li}$

yuanyilihao123@163.com

Xian Zhang

zhangxian@nwsuaf.edu.cn

Specialty section:

This article was submitted to

Plant Abiotic Stress,

a section of the journal

Frontiers in Plant Science

Received: 29 September 2021 Accepted: 23 November 2021

Published: 17 December 2021

Citation:

Guo Y, Yan J, Su Z, Chang J, Yang J, Wei $C$, Zhang $Y$, Ma J, Zhang $X$ and Li H (2021) Abscisic Acid Mediates Grafting-Induced Cold Tolerance of Watermelon via Interaction With Melatonin and Methyl Jasmonate.

Front. Plant Sci. 12:785317.

doi: 10.3389/fpls.2021.785317

\section{Abscisic Acid Mediates Grafting- Induced Cold Tolerance of Watermelon via Interaction With Melatonin and Methyl Jasmonate}

\author{
Yanliang Guo, Jingyi Yan, Zhuangzhuang Su, Jingjing Chang, Jianqiang Yang, \\ Chunhua Wei, Yong Zhang, Jianxiang Ma, Xian Zhang* and Hao Li*
}

State Key Laboratory of Crop Stress Biology for Arid Areas, College of Horticulture, Northwest A\&F University, Yangling, China

Grafting is widely used to increase plant defense responses to various stresses. Graftinginduced cold tolerance is associated with the increase of the antioxidant potential of plants; however, the underlying mechanisms remain unclear. Here, we found that pumpkin rootstocks promote antioxidant enzyme activities and alleviate cold-induced oxidative damage, accompanied by increased abscisic acid (ABA), melatonin, and methyl jasmonate (MeJA) levels in leaves. Increased ABA accumulation in leaves was attributed partly to the increased $A B A$ levels in rootstocks. ABA induced antioxidant enzymes activities and the accumulation of melatonin and MeJA, while inhibition of ABA synthesis blocked the rootstock-induced antioxidant activity and the accumulation of melatonin and MeJA under cold stress. Melatonin and MeJA application also enhanced ABA accumulation in leaves after cold exposure, whereas inhibition of melatonin or MeJA synthesis attenuated the rootstock-induced increase of ABA. Moreover, melatonin and MeJA application alleviated cold-induced oxidative stress, but inhibition of melatonin or MeJA synthesis lowered the rootstock- or ABA-induced antioxidant potential and tolerance to cold. These findings indicate that $A B A$ plays an important role in the grafting-induced cold tolerance by promoting the accumulation of melatonin and MeJA, which in turn, promote ABA accumulation, forming a positive feedback loop.

Keywords: abscisic acid, antioxidant potential, cold, grafting, melatonin, methyl jasmonate, watermelon

\section{INTRODUCTION}

As sessile organisms, plants frequently suffer a variety of environmental stresses throughout their life. Cold stress, one of the most severe abiotic stresses, adversely affects plant growth and development. When the ambient temperature drops, air temperature declines faster than soil temperature and thus the above-ground parts of plants are more vulnerable to cold stress. Cold stress directly impairs multiple physiological processes and indirectly initiates oxidative damage through excessive production of harmful reactive oxygen species (ROS) such as $\mathrm{O}_{2}$ - $^{-}$ and $\mathrm{H}_{2} \mathrm{O}_{2}$ (Chinnusamy et al., 2007). Excess ROS can cause oxidative stress leading to lipid peroxidation damage, DNA strand breakage, protein denaturation, enzyme deactivation, and, 
finally, cell death (Bose et al., 2014). To ensure their adaptation and fitness under cold stress, plants have evolved sophisticated defense mechanisms.

In response to diverse environmental stresses, roots and shoots are nonindependent but communicate to optimize the plants' adaptation and resistance to stress. Root-to-shoot communication requires various long-distance signals such as RNAs, peptides, phytohormones, ROS, $\mathrm{Ca}^{2+}$, and electrical signals (Wang et al., 2019). For instance, in response to dehydration stress, root-derived signals such as peptides, hydraulic signals, ROS, and $\mathrm{Ca}^{2+}$ move to the leaves to promote stomatal closure and thereby reduce water loss (Yoshida et al., 2021).

Grafting is widely used to increase plant defense responses to various biotic or abiotic stresses and improve the production of various horticultural crops. In addition, grafting is also a crucial research tool to investigate the signal transduction mechanisms involved in root-to-shoot communication. By using grafting, Wang et al. (2019) found that root-knot nematode attacks induce the transmission of electrical and ROS signals from roots to leaves, resulting in increased JA accumulation and increased resistance.

Watermelon (Citrullus lanatus) is one of the most valuable vegetable crops worldwide. In 2018, it was cultivated on approximately 3.24 million hectares and reached a production of 103.93 million tons. ${ }^{1}$ As a thermophilic crop, watermelon is highly sensitive to cold stress (Rivero et al., 2001), which significantly limits the productivity of watermelon in winter or early spring. Our recent study has revealed that grafting onto tolerant rootstocks induces watermelon tolerance to cold stress, accompanied by increased melatonin and methyl jasmonate (MeJA) levels ( $\mathrm{Li}$ et al., 2021a). However, the mechanism by which tolerant rootstocks induce melatonin and MeJA accumulation of shoots in response to cold is still unclear.

The phytohormone abscisic acid (ABA) is a central regulator of plant defense against abiotic stresses (Danquah et al., 2014). In plants, pyruvate and glyceraldehydes-3-phosphate are catalyzed to form the early $\mathrm{C}_{5}$ precursor, which were catalyzed into xanthoxin (the $\mathrm{C}_{15}$ precursor of $\mathrm{ABA}$ ) by a series of enzymes, such as 9-cis-epoxycarotenoid dioxygenase (NCED; Wasilewska et al., 2008). Xanthoxin is converted to ABA by multiple ways, such as via abscisic alcohol, abscisic aldehyde, or xanthoxic acid (Danquah et al., 2014). Several studies have reported the interactions between ABA and melatonin or MeJA during plant response to abiotic stresses (Anderson et al., 2004; Adie et al., 2007; Li et al., 2015; Zhao et al., 2017). Caffeic acid $O$-methyltransferase (COMT) and allene oxide cyclase (AOC) are key enzymes for melatonin and MeJA biosynthesis, respectively, in plants (Pratiwi et al., 2017; Li et al., 2021a). The results presented by $\mathrm{Hu}$ et al. indicate that the ABA-induced increase in antioxidant capacity and salt tolerance of tomato plants is associated with the increased accumulation of melatonin (Hu et al., 2021). Wang et al. have demonstrated that ABA mediates red light-induced

${ }^{1}$ https://www.fao.org/ biosynthesis of jasmonic acids (JAs), which act downstream of ABA, to induce cold tolerance in tomato (Wang et al., 2016).

ABA can be generated in both shoots and roots (Schachtman and Goodger, 2008). Root-originated ABA acts as a longdistance signal that can move to shoots, where it elicits defense responses to various abiotic stresses (Schachtman and Goodger, 2008; Ntatsi et al., 2013; Li et al., 2018). In grafted cucumber plants, luffa rootstock-sourced ABA induces shoot tolerance against heat by regulating the expression of HEAT SHOCK PROTEIN 70 and csa-miR159b (Li et al., 2014a, 2016). These findings support the assumption that $\mathrm{ABA}$ also plays an essential role in the rootstock-enhanced cold tolerance of shoots. To examine this hypothesis, we studied the role of ABA and its crosstalk with melatonin and MeJA in rootstockenhanced shoot tolerance to cold stress. Our results revealed that ABA functions together with melatonin and MeJA to stimulate the antioxidant potential and cold tolerance in grafted watermelon seedlings. These findings provide new insights into the mechanisms underlying grafting-enhanced cold tolerance.

\section{MATERIALS AND METHODS}

\section{Plant Materials}

In this study, watermelon [Citrullus lanatus (Thunb.) Matsum. \& Nakai] cultivar Nongkeda No. 5 and pumpkin (Cucurbita moschata) cultivar Weizhen No. 1 were used. Watermelon and pumpkin seeds for rootstocks were directly planted in trays filled with commercial peat-based compost. Watermelon seeds for scion were sown with a seven-day delay. Once the scion cotyledons expanded, top insertion grafts were prepared (Davis et al., 2008). The grafted plants with watermelon or pumpkin rootstocks were designated as $\mathrm{Cl}$ or $\mathrm{Cm}$, respectively. The plants were cultured under the following conditions: $25^{\circ} \mathrm{C} / 18^{\circ} \mathrm{C}$ (day/ night) temperature, $12 \mathrm{~h} / 12 \mathrm{~h}$ (light/dark) photoperiod, $400 \mu \mathrm{mol} \mathrm{m}^{-2} \mathrm{~s}^{-1}$ photosynthetic photon flux density (PPFD), $65-75 \%$ relative humidity. The grafted plants were watered every 2 days and supplied with half-strength Hoagland's nutrient solution every 6 days.

\section{Experimental Design}

Four-leaf stage $\mathrm{Cl}$ and $\mathrm{Cm}$ seedlings were transferred into growth chambers at $25^{\circ} \mathrm{C}$ for the control treatment or $4^{\circ} \mathrm{C}$ for the cold treatment. At $12 \mathrm{~h}$ after exposure to $4^{\circ} \mathrm{C}$, the leaf and root samples and xylem sap exudates were collected for hormone quantification and gene expression assays. At $36 \mathrm{~h}$, the redox homeostasis and cold tolerance of plants were analyzed.

To investigate the effects of exogenous ABA, melatonin, or MeJA on plant tolerance to cold-induced oxidative stress, each $\mathrm{Cl}$ seedling was sprayed with $20 \mathrm{ml}$ ABA $(100 \mu \mathrm{m}$; Fu et al., 2017), melatonin $(150 \mu \mathrm{m}$; Li et al., 2021a), MeJA $(200 \mu \mathrm{m}$; Li et al., 2021a). For preparation of these solutions, the ABA (CAS: $14375-45-2,98 \%$ ), melatonin (CAS: $73-31-4, \geq 98 \%$ ), or 


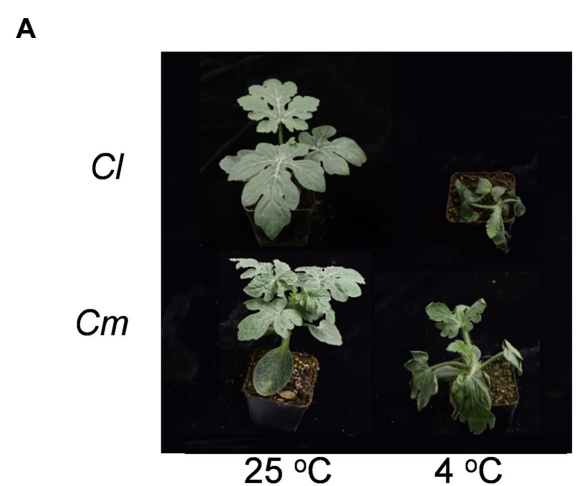

B

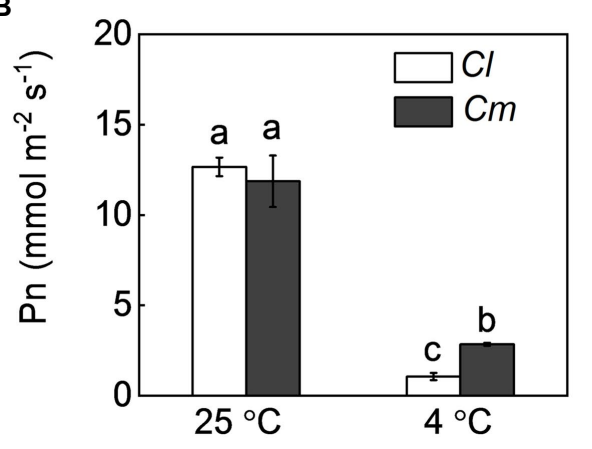

C

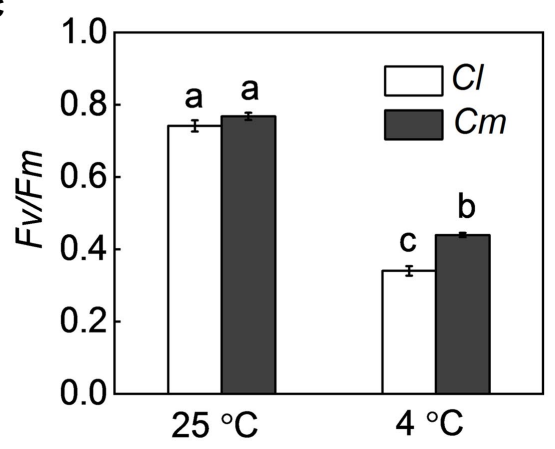

D

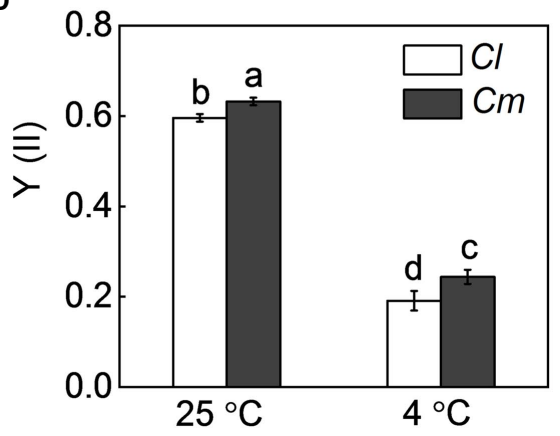

FIGURE 1 | Pumpkin rootstock-alleviated cold-induced wilting and decrease of photosynthetic performance in watermelon shoots. Self-grafted (Cl) and pumpkingrafted $(\mathrm{Cm})$ watermelon plants were exposed to cold stress at $4^{\circ} \mathrm{C}$. After cold treatment for $36 \mathrm{~h}$, the (A) phenotypes, (B) net photosynthetic rate $(\mathrm{Pn})$, (C) photochemical efficiency of PSII (FV/Fm), and (D) quantum yield of PSII [Y(II)] were analyzed. Data are reported as means \pm standard deviations $(n=6)$. Different letters indicated significant difference at $p<0.05$.

MeJA (CAS: 39924-52-2, $\geq 98 \%$ ), purchased from Sigma-Aldrich (St. Louis, MO, United States), was dissolved in absolute ethanol, followed by a $1 / 10,000(\mathrm{v} / \mathrm{v})$ dilution in distilled water. The same proportion of diluted absolute ethanol in distilled water was used as the control. After $12 \mathrm{~h}$, the seedlings were transferred to $4^{\circ} \mathrm{C}$. To inhibit the biosynthesis of melatonin or MeJA, the $\mathrm{Cl}$ plants were sprayed with $100 \mu \mathrm{m}$ p-chlorophenyl alanine (CPA, an inhibitor of melatonin biosynthesis, CAS: 7424-00-2, Sigma-Aldrich, $\geq 98.5 \%$; Park, 2011; Wen et al., 2016) or $5 \mathrm{~mm}$ diethyldithiocarbamic acid (DIECA, an inhibitor of JA synthesis, CAS: 1518-58-7, Sigma-Aldrich, 97\%; Hu et al., 2003), respectively. CPA and DIECA solutions were prepared as ABA. After $8 \mathrm{~h}$, the plants were treated with ABA. Twelve hours later, the seedlings were transferred to $4^{\circ} \mathrm{C}$. The leaf samples were taken at $12 \mathrm{~h}$ after cold treatment for hormone quantification and gene expression assays and at $36 \mathrm{~h}$ for cold tolerance analysis.

To determine the involvement of $\mathrm{ABA}$, melatonin, and MeJA in pumpkin rootstock-alleviated, cold-induced oxidative stress, $C m$ plants were sprayed with $50 \mu \mathrm{m}$ fluridone (an ABA synthesis inhibitor; CAS: 59756-60-4, Sigma-Aldrich, $\geq 98 \%$; Fu et al., 2017), CPA, or DIECA, respectively. Fluridone solution was prepared as ABA. In addition to fluridone spraying, the roots of each plant were watered with $50 \mathrm{ml}$ of $25 \mu \mathrm{m}$ fluridone. After $8 \mathrm{~h}$, the plants were transferred to $4^{\circ} \mathrm{C}$. The leaf samples were taken at $12 \mathrm{~h}$ after cold treatment for hormone quantification and gene expression assays and at $36 \mathrm{~h}$ for cold tolerance analysis.

\section{Analysis of the Net Photosynthetic Rate (Pn) and Chlorophyll Fluorescence}

The Pn was measured on the third leaf from the bottom of seedlings using a portable photosynthesis system (LI-6400, Li-Cor, Lincoln, NE, United States) under the following conditions: $25^{\circ} \mathrm{C}$ temperature, $400 \mu \mathrm{mol} \mathrm{m}^{-2} \mathrm{~s}^{-1}$ PPFD, and $380 \mu \mathrm{mol} \mathrm{mol}^{-1} \quad \mathrm{CO}_{2}$. The maximal quantum yield of photosystem (PS) II $(F v / F m)$ and the quantum yield of PSII [Y(II)] were determined by using a pulse-amplitude modulated chlorophyll fluorometer (imaging-PAM, Heinz Walz GmbH, Effeltrich, Germany) after plants were kept in the dark for $30 \mathrm{~min}$.

\section{Quantification of ABA, Melatonin, and Meja and Xylem Sap Collection}

ABA and MeJA were extracted following the methods described previously (Yang et al., 2001; Pan et al., 2010). In brief, $0.5 \mathrm{~g}$ of frozen samples was homogenized in $5 \mathrm{ml}$ of 1-propanol/ $\mathrm{H}_{2} \mathrm{O} /$ concentrated $\mathrm{HCl}(2 / 1 / 0.002$, v/v/v). After overnight incubation, the extracts were mixed with $5 \mathrm{ml}$ of dichloromethane. The mixture was shaken for $30 \mathrm{~min}$ at $4^{\circ} \mathrm{C}$. After centrifugation at $15,000 \mathrm{~g}$ for $5 \mathrm{~min}$ at $4^{\circ} \mathrm{C}$, the obtained lower phase was dried using $\mathrm{N}_{2}$ gas. The residue was then dissolved in methanol. The concentrations of ABA or MeJA were measured using an ELISA kit according to the manufacturer's instructions (China Agricultural University, Beijing, China). 
A
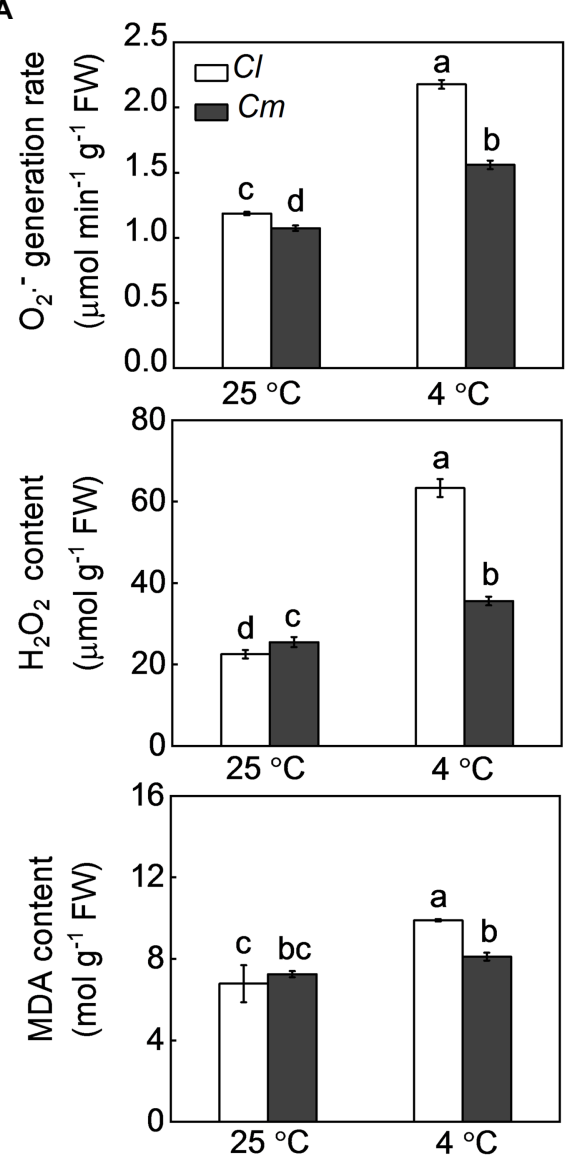

B
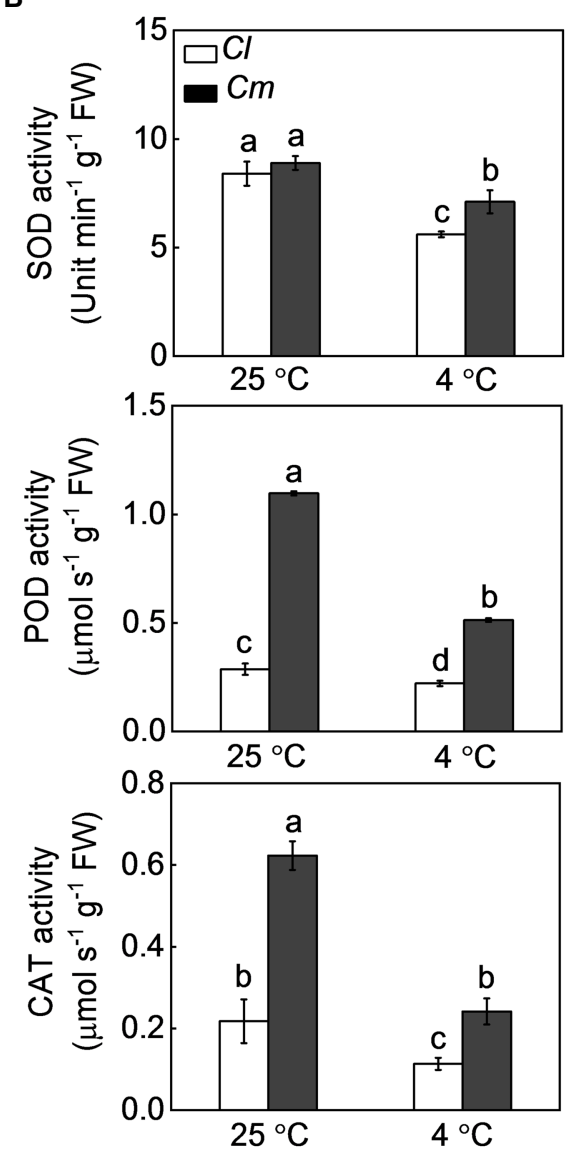

FIGURE 2 | Pumpkin rootstock-alleviated cold-induced oxidative damage in watermelon shoots. The seedlings were treated according to the procedures outlined in Figure 1. (A), The levels of $\mathrm{O}_{2} \cdot{ }^{-}, \mathrm{H}_{2} \mathrm{O}_{2}$, and malondialdehyde (MDA). (B) The activities of superoxide dismutase (SOD), peroxidase (POD), and catalase (CAT). Data are reported as means \pm standard deviations $(n=3)$. Different letters indicated significant difference at $p<0.05$.

Melatonin was extracted using a method developed by Pape and Lüning (2006). Frozen leaf samples ( $0.5 \mathrm{~g})$ were homogenized in $5 \mathrm{ml}$ of acetone-methanol buffer (acetone/methanol/ water $=89 / 10 / 1, \mathrm{v} / \mathrm{v} / \mathrm{v}$ ) on ice. The homogenate was centrifuged at $5,000 \mathrm{~g}$ for $10 \mathrm{~min}$ at $4^{\circ} \mathrm{C}$. Then the supernatant was mixed with $0.5 \mathrm{ml}$ of trichloric acid (1\%). After centrifugation at $10,000 \mathrm{~g}$ for $10 \mathrm{~min}$ at $4^{\circ} \mathrm{C}$, the melatonin level was measured using an ELISA kit (Shanghai Lanpai Biotech Co., Ltd., Shanghai, China).

For xylem sap collection, the stem was cut $5 \mathrm{~cm}$ above the soil surface, and the cut surface was blotted dry 3 times using sterile filter paper. The xylem sap exudates were collected using micropipette tips (Li et al., 2014a). ABA exudation rate was calculated according to the sap exudation rate and ABA content in xylem sap (Supplementary Figure S1).

\section{Analysis of $\mathrm{H}_{2} \mathrm{O}_{2}, \mathrm{O}_{2^{-}}$, Malondialdehyde, and Relative Electric Conductivity}

Analysis of $\mathrm{H}_{2} \mathrm{O}_{2}$ was conducted as reported in Willekens et al. (1997). $\mathrm{H}_{2} \mathrm{O}_{2}$ was extracted from leaf samples $(0.3 \mathrm{~g})$ in $1 \mathrm{M}$
$\mathrm{HClO}_{4}(3 \mathrm{ml})$. After centrifugation at $6,000 \mathrm{~g}$ for $5 \mathrm{~min}$ at $4^{\circ} \mathrm{C}$, the supernatants were adjusted to $\mathrm{pH} 6.0-7.0$ with $\mathrm{KOH}(4 \mathrm{M})$ and filtered using Bio-Rad AG1x8 columns (Hercules, CA, United States). After elution with double distilled water, the samples $(800 \mu \mathrm{l})$ were mixed with $400 \mu \mathrm{l} 100 \mathrm{~mm}$ potassium acetate buffer ( $\mathrm{pH} 4.4)$ containing $4 \mathrm{~mm}$ 2,2'-azino-di (3-ethylbenzthiazoline-6-sulfonic acid), $400 \mu \mathrm{l}$ deionized water, and $0.25 \mathrm{U}$ of horseradish peroxidase. The $\mathrm{H}_{2} \mathrm{O}_{2}$ content was detected at $\mathrm{OD}_{412}$.

$\mathrm{O}_{2} .^{-}$analysis was performed as reported in Elstner and Heupel (1976). Leaf samples $(0.5 \mathrm{~g})$ were homogenized in $3 \mathrm{ml}$ of $65 \mathrm{~mm}$ potassium phosphate buffer ( $\mathrm{pH}$ 7.8). After centrifugation, the supernatant $(1 \mathrm{ml})$ was mixed with $65 \mathrm{~mm}$ phosphate buffer $(\mathrm{pH} 7.8,0.9 \mathrm{ml})$ and $10 \mathrm{~mm}$ hydroxylamine hydrochloride $(0.1 \mathrm{ml})$. The mixture was incubated at $25^{\circ} \mathrm{C}$ for $20 \mathrm{~min}$ and then, they were mixed with $17 \mathrm{~mm}$ sulfanilamide and $7 \mathrm{~mm}$ a-naphthylamine. After reaction at $25^{\circ} \mathrm{C}$ for $20 \mathrm{~min}$, the mixture was mixed with ethyl ether in the same volume. After centrifugation at $1,500 \mathrm{~g}$ for $5 \mathrm{~min}$, the $\mathrm{O}_{2}{ }^{-}$production was detected at $\mathrm{OD}_{530}$.

Malondialdehyde (MDA), as an index of lipid peroxidative damage, was determined using 2-thiobarbituric acid following 
A

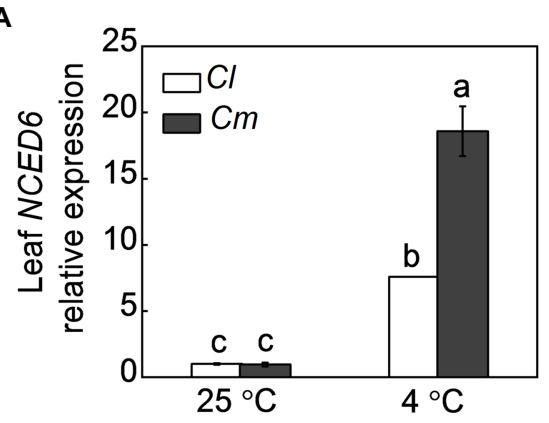

C

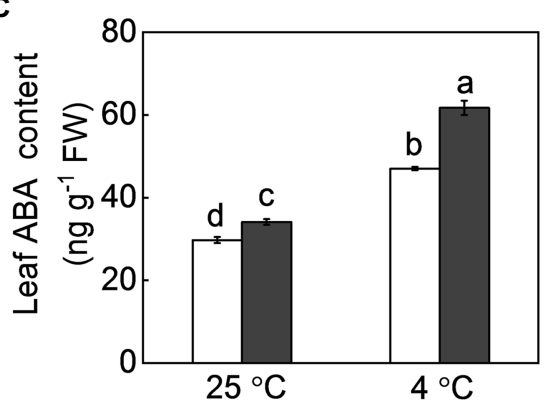

B

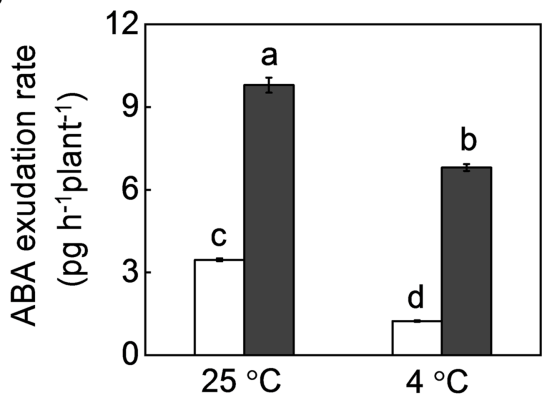

D

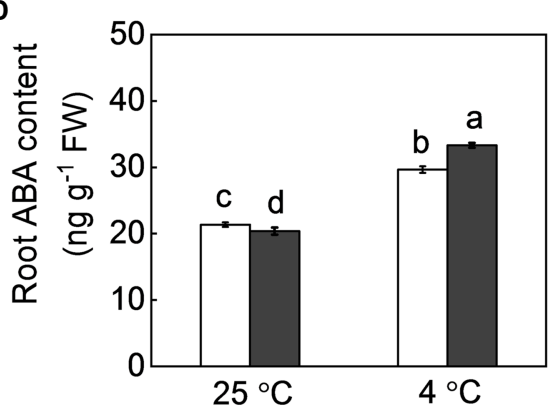

FIGURE 3 | ABA accumulation and transport via the xylem in response to cold in grafted watermelon plants. (A) The transcript levels of 9-C/S-

EPOXYCAROTENOID DIOXYGENASE 6 (NCED6) in leaves. (B) ABA contents in leaves. (C) ABA exudation rates from the xylem. (D) ABA contents in roots. Selfgrafted $(C l)$ and pumpkin-grafted $(\mathrm{Cm})$ watermelon plants were exposed to cold stress at $4^{\circ} \mathrm{C}$. Samples of roots, leaves, and xylem sap were collected at $12 \mathrm{~h}$ after cold exposure. Data are reported as means \pm standard deviations $(n=3)$. Different letters indicated significant difference at $p<0.05$.
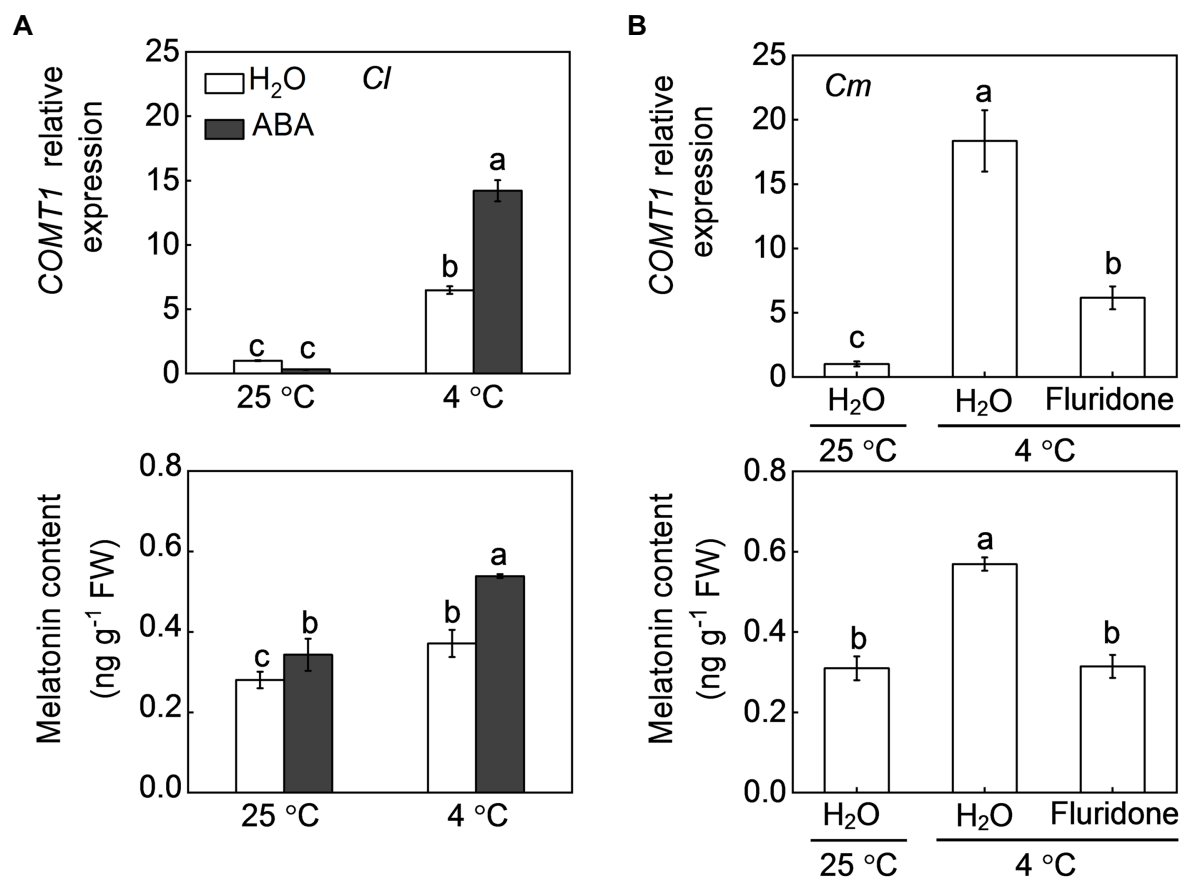

FIGURE 4 | Involvement of ABA in pumpkin rootstock-mediated melatonin accumulation in watermelon leaves in response to cold. (A) The effects of ABA on the levels of the CAFFEIC ACID O-METHYLTRANSFERASE 1 (COMT1) transcript and melatonin in leaves of self-grafted plants (Cl) under cold exposure. The leaves of $\mathrm{Cl}$ seedlings were sprayed with $100 \mu \mathrm{m} \mathrm{ABA}$ or $\mathrm{H}_{2} \mathrm{O}$ (Control). Twelve hours later, the seedlings were exposed to cold stress at $4^{\circ} \mathrm{C}$ for $12 \mathrm{~h}$. (B) The effects of fluridone on COMT1 transcript and melatonin levels in leaves of pumpkin-grafted plants $(\mathrm{Cm})$ under cold exposure. The leaves of $\mathrm{Cm}$ seedlings were sprayed with $50 \mu \mathrm{m}$ fluridone. Meanwhile, the seedlings were irrigated with $25 \mu \mathrm{m}$ fluridone. Eight hours later, the seedlings were exposed to cold stress at $4^{\circ} \mathrm{C}$ for $12 \mathrm{~h}$. Data are reported as means \pm standard deviations $(n=3)$. Different letters in $\mathbf{( A )}$ and $\mathbf{( B )}$ indicated significant difference at $p<0.05$. 

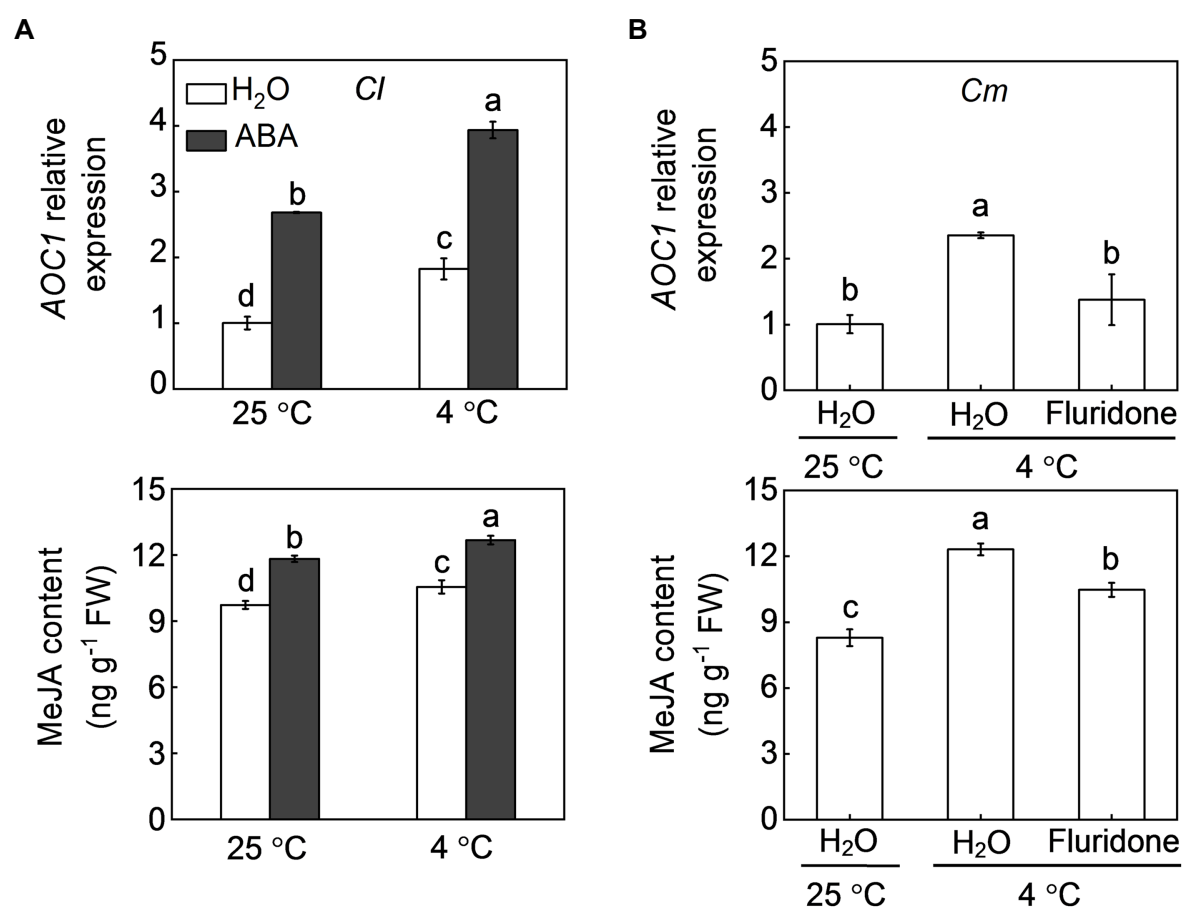

FIGURE 5 | Involvement of ABA in pumpkin rootstock-induced methyl jasmonate (MeJA) accumulation in watermelon shoots under cold stress. (A) The effects of ABA on the transcript levels of ALLENE OXIDE CYCLASE 1 (AOC1) and MeJA accumulation in leaves of self-grafted plants (C/) under cold exposure. (B) The effects of fluridone on the transcript levels of $A O C 1$ and MeJA accumulation in leaves of pumpkin-grafted plants $(\mathrm{Cm})$ under cold exposure. The seedlings were treated according to the procedures outlined in Figure 4. Data are reported as means \pm standard deviations $(n=3)$. Different letters in $(\mathbf{A})$ and $\mathbf{( B )}$ indicated significant difference at $p<0.05$.

the method of Hodges et al. (1999). The relative electric conductivity (REC) was determined following the method of Zhou and Leul (1998).

\section{Analysis of Antioxidant Enzyme Activities}

The activities of antioxidant enzymes in leaves were analyzed using spectrophotometric methods. For enzyme extraction, leaf samples $(0.3 \mathrm{~g})$ were ground in $3 \mathrm{ml} 25 \mathrm{~mm}$ HEPES buffer $(\mathrm{pH}$ $7.8,0.2 \mathrm{~mm}$ EDTA, $2 \mathrm{~mm}$ ascorbic acid, and $2 \%$ polyvinyl pyrrolidone) on ice. Superoxide dismutase (SOD) activity was analyzed following the method developed by Stewart and Bewley (1980) based on photochemical reduction of NBT. Peroxidase (POD) activity was measured following the method of Cakmak and Marschner (1992). Catalase (CAT) activity was measured as a decline in A240 according to the method of Patra et al. (1978). Developed by Stewart and Bewley (1980).

\section{Analysis of Gene Expression}

Total RNA was extracted using the RNA extraction kit from Axgen (Union City, CA, United States) according to the manufacturer's instructions. After extraction, the RNA samples were treated with gDNase to remove DNA, then reversetranscribed ( $1 \mu \mathrm{g}$ per sample) to cDNA using a ReverTra Ace qPCR RT kit (Toyobo, Osaka, Japan). Quantitative Real-Time PCR was conducted using SYBR Premix ExTaqII $(2 \times)$ Kit (Takara, Tokyo, Japan) on an iCycler Iq TM Multicolor PCR
Detection System (Bio-Rad, Hercules, CA, United States; Li et al., 2017). $\beta$-ACTIN was used as an internal control gene. Primers used for gene expression analyses are listed in Supplementary Table S1. The relative expression of genes was calculated using the $2^{-\Delta \Delta C T}$ method as reported in Livak and Schmittgen (2001).

\section{Statistical Analysis}

The experiments were laid out in a completely randomized design. All experiments were repeated three times, and each experiment contained at least 15 seedlings per treatment. Data are presented as means \pm standard deviations (SD). The differences among treatments were determined via one-way or two-way variance (ANOVA) using SPSS package (SPSS 19.0, Chicago, IL, United States), followed by Tukey's test at $p<0.05$. Significant differences were indicated by different letters.

\section{RESULTS}

\section{Pumpkin Rootstocks Alleviate Cold-Induced Oxidative Damage in Watermelon Leaves}

We examined the changes in the plant phenotypes, Pn, Fv/ $\mathrm{Fm}$, and Y(II) of watermelon shoots grafted onto watermelon 
A

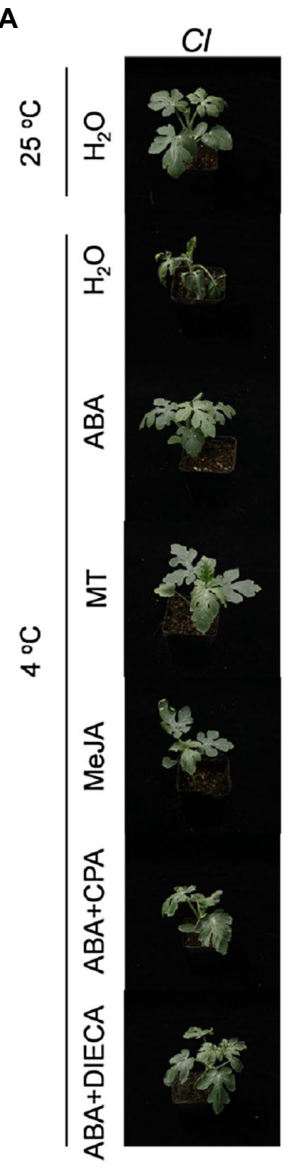

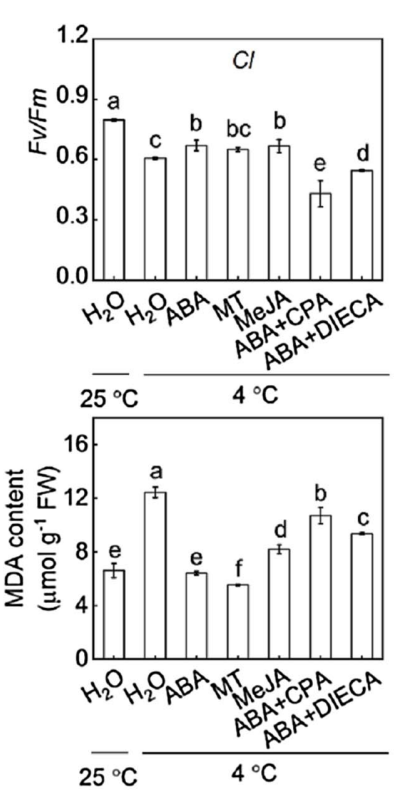

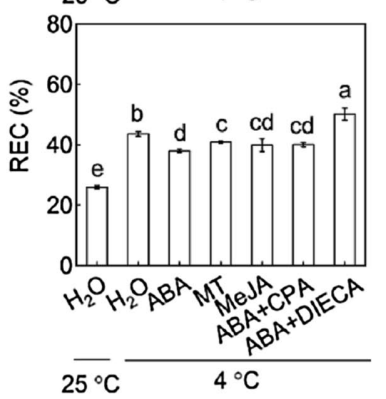

B

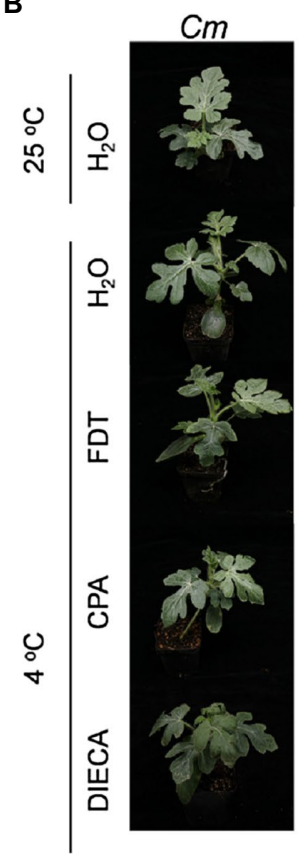

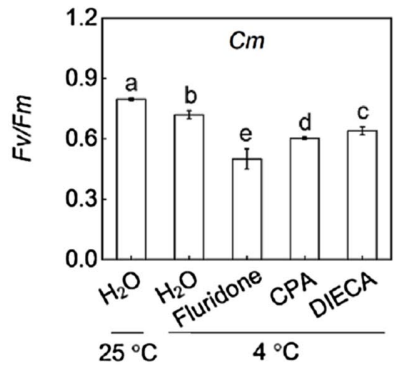
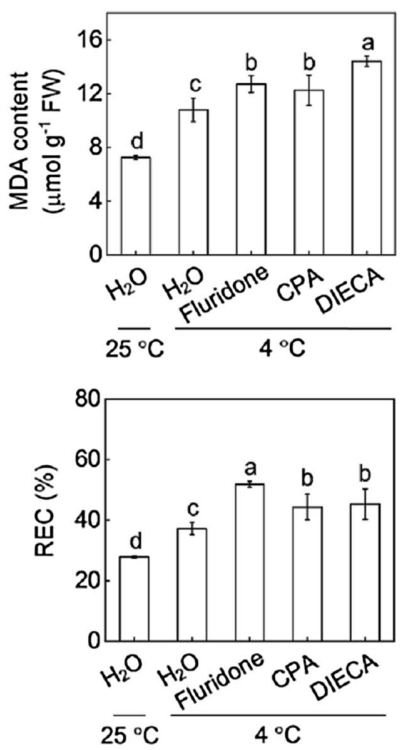

FIGURE 6 | Involvement of melatonin and MeJA in ABA-mediated cold tolerance in grafted watermelon plants. In (A), the leaves of self-grafted (C/) plants were sprayed with ABA $(100 \mu \mathrm{m})$, melatonin $(150 \mu \mathrm{m})$, MeJA $(200 \mu \mathrm{m})$ or $\mathrm{H}_{2} \mathrm{O}$ (Control). Twelve hours later, the plants were exposed to cold stress at $4^{\circ} \mathrm{C}$. To inhibit melatonin or MeJA synthesis, the plants were sprayed with p-chlorophenyl alanine (CPA, $100 \mu \mathrm{m}$ ) or diethyldithiocarbamic acid (DIECA, $5 \mathrm{~mm}$ ), respectively, eight hours prior to ABA application. After cold treatment for $36 \mathrm{~h}$, the phenotypes, photochemical efficiency of PSII (FV/Fm), malondialdehyde (MDA), and relative electric conductivity (REC) were analyzed. In (B), pumpkin-grafted plants $(\mathrm{Cm})$ were sprayed with $\mathrm{CPA}$ or DIECA 8 hours prior to cold exposure at $4{ }^{\circ} \mathrm{C}$. After $36 \mathrm{~h}$ of cold treatment, the phenotypes, Fv/Fm, MDA, and REC were analyzed. Data are reported as means \pm standard deviations $(n=3)$. Different letters indicated significant difference at $p<0.05$.

$(\mathrm{Cl})$ or pumpkin $(\mathrm{Cm})$. Under normal conditions, no significant differences were found in seedling growth, $\mathrm{Pn}$, or $\mathrm{Fv} / \mathrm{Fm}$ between $\mathrm{Cl}$ and $\mathrm{Cm}$ plants (Figure 1). Exposure to $4^{\circ} \mathrm{C}$ resulted in obvious plant wilting and significant decreases in $\mathrm{Pn}, \mathrm{Fv} / \mathrm{Fm}$, and $\mathrm{Y}(\mathrm{II})$ in watermelon leaves. However, pumpkin rootstocks attenuated the cold-induced wilting and reduction in Pn, Fv/ $\mathrm{Fm}$, and $\mathrm{Y}(\mathrm{II})$. After exposure to $4^{\circ} \mathrm{C}$ for $36 \mathrm{~h}, \mathrm{Pn}, \mathrm{Fv} / \mathrm{Fm}$, and $\mathrm{Y}(\mathrm{II})$ in $\mathrm{Cm}$ plants were 168.3, 29.2, and $27.7 \%$ higher than in $\mathrm{Cl}$ plants, respectively.

We then investigated the effects of the pumpkin rootstock on the antioxidant potential and oxidative damage in watermelon plants in response to cold. Under normal conditions, $\mathrm{Cl}$ and $\mathrm{Cm}$ plants showed similar generation rates of $\mathrm{O}_{2} \cdot{ }^{-}$and similar levels of $\mathrm{H}_{2} \mathrm{O}_{2}$ and MDA. Cold exposure caused a significant increase of $\mathrm{O}_{2} \cdot{ }^{-}, \mathrm{H}_{2} \mathrm{O}_{2}$, and MDA levels, which was more apparent in $\mathrm{Cl}$ plants than in $\mathrm{Cm}$ plants (Figure 2A). SOD, POD, and CAT are well-studied, key antioxidant enzymes that can scavenge excess ROS. In $\mathrm{Cl}$ and $\mathrm{Cm}$ plants, SOD, POD, and CAT were significantly reduced by cold (Figure 2B). Interestingly, $\mathrm{Cm}$ plants exhibited higher activities of these three enzymes than $\mathrm{Cl}$ plants under cold stress. For instance, SOD, POD, and CAT activities in $\mathrm{Cm}$ plants were 26.8, 131.8, and $113.1 \%$ higher than in $\mathrm{Cl}$ plants after exposure to cold, respectively.

\section{Involvement of ABA in the Rootstock- Induced Increase of Melatonin and Meja Accumulation}

As ABA is an essential root-to-shoot signal in plant defense against various environmental stresses, the response of $\mathrm{ABA}$ to cold stress was analyzed in grafted plants. Under normal conditions, $\mathrm{Cm}$ plants showed higher ABA content in leaves and a higher ABA exudation rate than $\mathrm{Cl}$ plants (Figure 3). In $\mathrm{Cl}$ and $\mathrm{Cm}$ plants, cold stress increased the accumulation of $\mathrm{ABA}$ in roots and leaves and the transcript levels of 
A
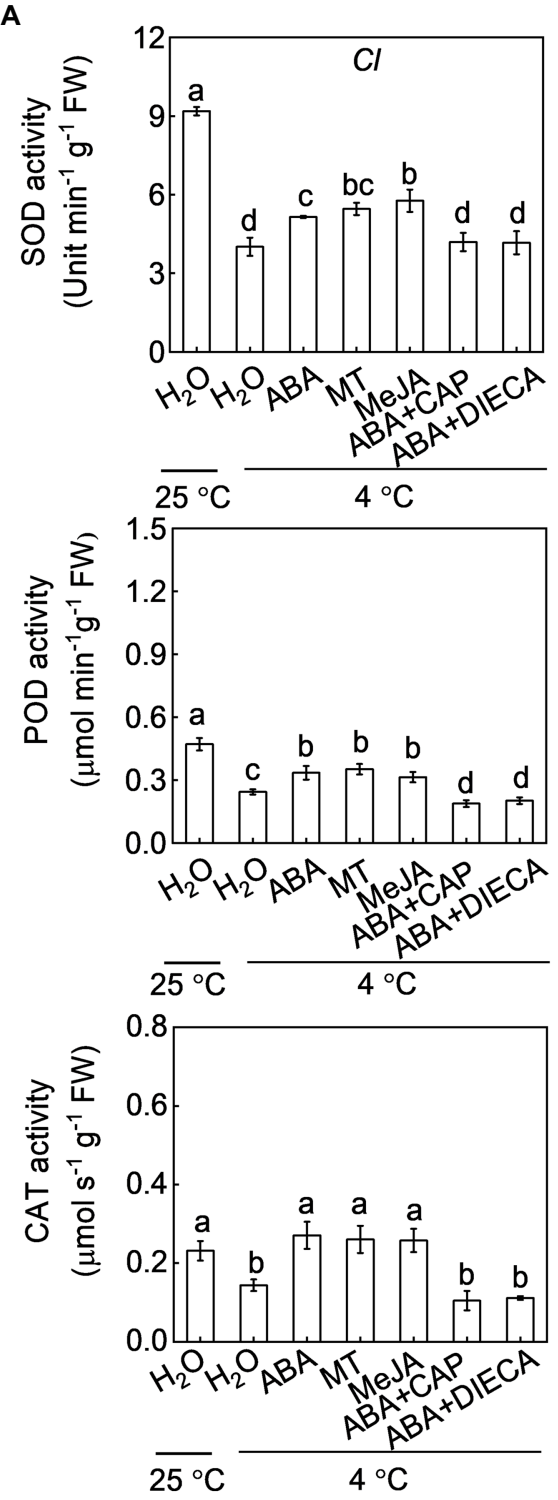

B
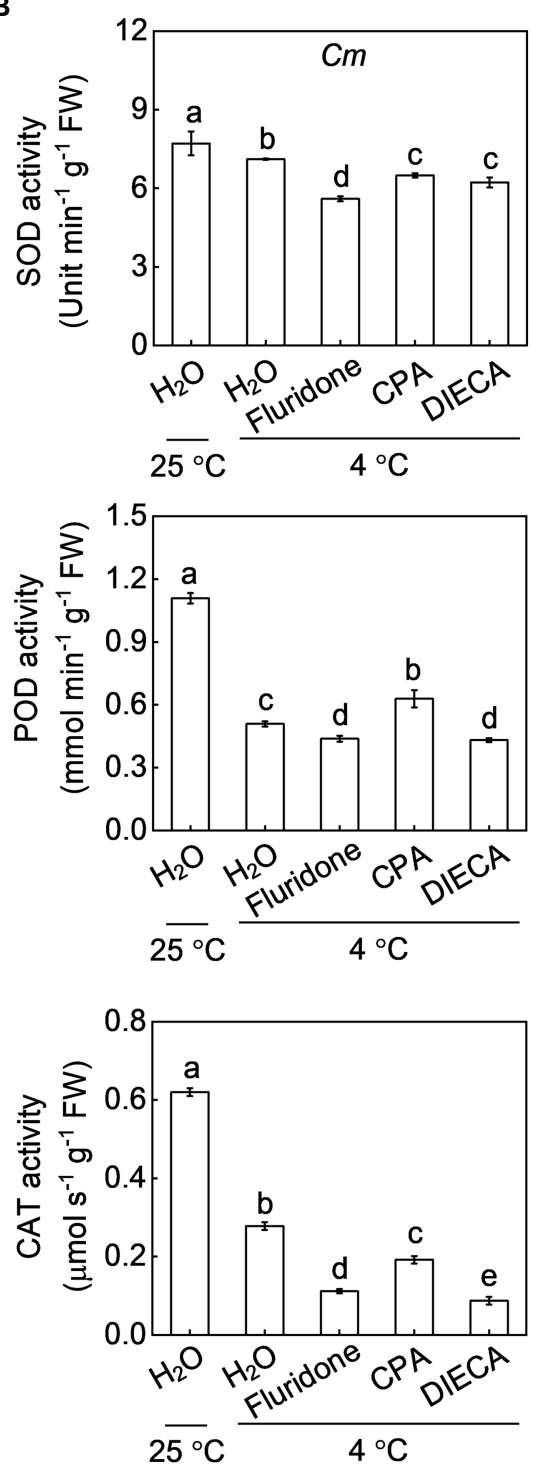

FIGURE 7 | Involvement of melatonin and MeJA in the ABA-induced increase of the antioxidant capacity in grafted watermelon plants under cold stress. The seedlings were treated according to the procedures outlined in Figure 6. After cold treatment for $36 \mathrm{~h}$, the activities of superoxide dismutase (SOD), peroxidase (POD), and catalase (CAT) in (A) self-grafted $(C l)$ and $\mathbf{( B )}$ pumpkin-grafted $(\mathrm{Cm})$ plants. Data are reported as means \pm standard deviations $(n=3)$. Different letters indicated significant difference at $p<0.05$.

NCED6 in leaves but reduced the rate of ABA exudation from the xylem. Interestingly, $\mathrm{Cm}$ plants showed higher NCED6 transcript levels in leaves, ABA accumulation in roots and leaves, and $\mathrm{ABA}$ exudation rates than $\mathrm{Cl}$ plants after exposure to cold.

Pumpkin rootstocks increased melatonin contents and the transcript levels of CAFFEIC ACID O-METHYLTRANSFERASE 1 (COMT1), a key gene in melatonin synthesis, in watermelon leaves under cold stress (Figure 4; Li et al., 2021a). Similar to pumpkin rootstocks, exogenous $\mathrm{ABA}$ at $100 \mu \mathrm{m}$ promoted melatonin accumulation in watermelon leaves under both normal conditions and cold stress and upregulated the relative expression of COMT1 after cold exposure. However, pretreatment with fluridone $(50 \mu \mathrm{m})$, which can inhibit ABA biosynthesis, completely abolished the pumpkin rootstockinduced upregulation of COMT1 and accumulation of melatonin under cold stress. Like melatonin, MeJA biosynthesis in watermelon leaves was promoted by pumpkin rootstocks and ABA after cold exposure, as reflected by increased MeJA accumulation and upregulation of $A O C 1$, a key gene involved in MeJA synthesis (Figure 5). However, inhibition of ABA biosynthesis by fluridone prevented the pumpkin rootstockinduced MeJA accumulation and AOC1 expression after cold exposure. 
A
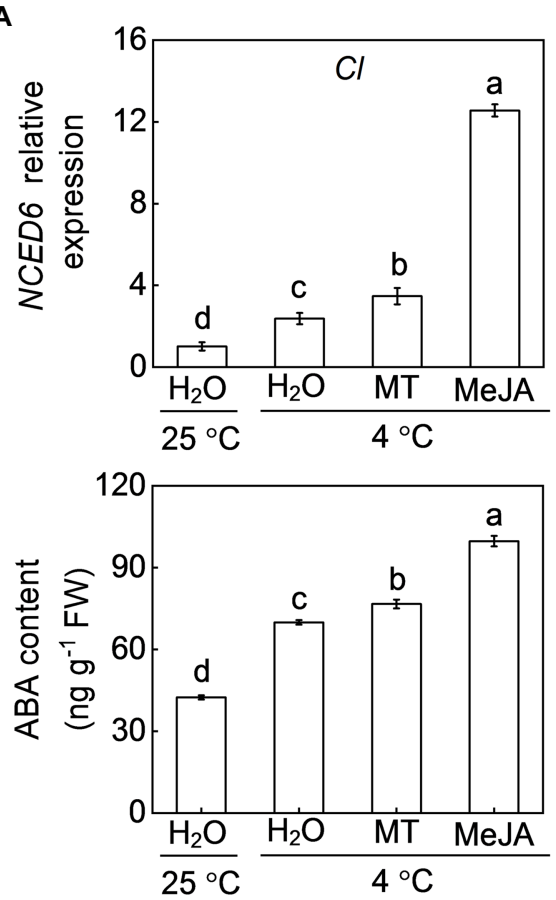

B
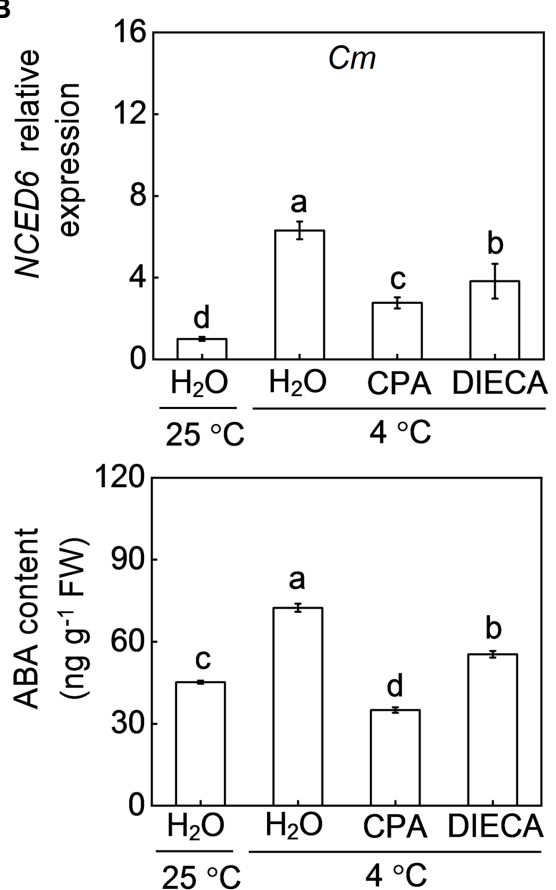

FIGURE 8 | Involvement of melatonin and MeJA in pumpkin rootstock-induced ABA accumulation in leaves under cold exposure. In (A), the leaves of self-grafted (Cl) plants were sprayed with melatonin $(150 \mu \mathrm{m})$, MeJA $(200 \mu \mathrm{m})$ or $\mathrm{H}_{2} \mathrm{O}\left(\right.$ Control). Twelve hours later, the plants were exposed to cold stress at $4{ }^{\circ} \mathrm{C}$ for $12 \mathrm{~h}$. In (B), the leaves of pumpkin-grafted plants $(\mathrm{Cm})$ were sprayed with $\mathrm{CPA}$, DIECA, or $\mathrm{H}_{2} \mathrm{O}$ (Control). Eight hours later, the plants were exposed to cold stress at $4^{\circ} \mathrm{C}$ for $12 \mathrm{~h}$. The relative expression of 9-CIS-EPOXYCAROTENOID DIOXYGENASE 6 (NCED6) and ABA levels in leaves of (A) self-grafted (Cl) and (B) pumpkin-grafted (Cm) plants were analyzed. Data are reported as means \pm standard deviations $(n=3)$. Different letters indicated significant difference at $p<0.05$.

\section{Involvement of Melatonin and Meja in Rootstock- and ABA-Induced Increase of the Antioxidant Potential and Cold Tolerance}

Pretreatment with ABA at $100 \mu \mathrm{m}$, melatonin at $150 \mu \mathrm{m}$, or MeJA at $200 \mu \mathrm{m}$ enhanced cold tolerance in $\mathrm{Cl}$ plants, as reflected by the alleviation of plant wilting, increase in $\mathrm{Fv} / \mathrm{Fm}$, and decrease in MDA and REC (Figure 6A). The MDA content in ABA-, melatonin-, and MeJA-pretreated plants was 35.1, 44.0 and $17.1 \%$ lower, respectively, than that in $\mathrm{H}_{2} \mathrm{O}$-pretreated plants after cold exposure. However, inhibition of ABA biosynthesis by fluridone abolished the pumpkin rootstock-induced alleviation of plant wilting, increase in $F v / F m$, and decreases in MDA and REC under cold stress (Figure 6B). Moreover, inhibition of melatonin or MeJA biosynthesis by CPA $(100 \mu \mathrm{m}$, Supplementary Figure S2) or DIECA $(5 \mathrm{~mm})$, respectively, attenuated or abolished the pumpkin rootstock- or ABA-induced increase in $\mathrm{Fv} / \mathrm{Fm}$ and decreases in MDA and REC under cold stress.

Exogenous application of ABA, melatonin, or MeJA increased the SOD, POD, and CAT activities in $\mathrm{Cl}$ seedlings under cold stress (Figure 7A). For instance, SOD activity in ABA-, melatonin-, and MeJA-pretreated plants was 28.4, 36.0 and $43.8 \%$ higher, respectively, than that in $\mathrm{H}_{2} \mathrm{O}$-pretreated plants after cold exposure. However, pretreatment with fluridone attenuated or abolished the pumpkin rootstock-induced increase in SOD, POD, and CAT activities under cold stress (Figure 7B).
Moreover, pretreatment with CAP or DIECA attenuated or abolished the pumpkin rootstock- or ABA-induced increases in the activities of these enzymes after cold exposure, except that the POD activity was increased by CPA in $\mathrm{Cm}$ plants.

\section{Involvement of Melatonin and Meja in Rootstock-Induced ABA Accumulation Under Cold Stress}

To investigate whether melatonin or MeJA increase ABA levels in a positive feedback manner, we examined the $\mathrm{ABA}$ response to melatonin and MeJA. ABA accumulation in $\mathrm{Cl}$ leaves after cold exposure was increased by exogenous melatonin $(9.7 \%)$ and MeJA (42.6\%), accompanied by an up-regulation of NCED6 (Figure 8A). However, CPA or DIECA pretreatment abolished or attenuated the pumpkin rootstock-increased transcript levels of NCED6 and accumulation of ABA (Figure 8B).

\section{DISCUSSION}

\section{Melatonin and Meja Are Involved in Rootstock-Alleviated Cold-Induced Oxidative Stress}

A common adverse effect of cold stress is the excessive accumulation of ROS by inhibition of the photosynthetic electron transport (Dat et al., 2000). It has been reported 
that grafting onto tolerant rootstocks can enhance the antioxidant potential and thus alleviate cold-induced oxidative damage in cucumber shoots ( $\mathrm{Li}$ et al., 2014b). In this study, our results show that grafting onto pumpkin increased the activities of SOD, POD, and CAT and alleviated cold-induced accumulation of $\mathrm{O}_{2}{ }^{-}$and $\mathrm{H}_{2} \mathrm{O}_{2}$ and oxidative damage in watermelon shoots. These findings suggest that pumpkin (Cucurbita moschata, a chilling-tolerant species) rootstocks enhance the cold tolerance of watermelon shoots and such role of pumpkin rootstocks is associated with the induction of antioxidant potential (Figures 1, 2).

Melatonin and MeJA are well known to play critical roles in plant responses to multiple environmental stresses (Arnao and Hernández-Ruiz, 2014; Kazan, 2015). Various studies have proven that melatonin is an important antioxidant that can scavenge excess ROS directly or indirectly by inducing an antioxidant system in plants (Zhang and Zhang, 2014; Zhang et al., 2015). Like melatonin, MeJA also enhances stress tolerance by increasing the antioxidant potential and thereby tolerance to oxidative damage (Ali and Baek, 2020). Our recent study has demonstrated that melatonin and MeJA play essential roles and interact with each other in grafting-enhanced watermelon tolerance to cold stress (Li et al., 2021a). During grafted watermelon response to cold stress, melatonin promotes the accumulation of MeJA, which in turn induces melatonin accumulation, forming a forming a self-propagating mutual activation loop that enhances cold tolerance. Consistently, the current results show that pumpkin rootstocks increase the accumulation of melatonin and MeJA in watermelon leaves under cold stress (Figures 4, 5). Pretreatment with melatonin or MeJA increased the antioxidant potential and, consequently, the tolerance to cold-induced oxidative stress in $\mathrm{Cl}$ plants; however, inhibition of melatonin or MeJA synthesis by pretreatment with CPA or DIECA attenuated rootstock-alleviated oxidative damage under cold stress (Figures 6, 7). Taken together, these data indicate that melatonin and MeJA are involved in the rootstock-induced increase of antioxidant potential and consequent cold tolerance. However, further studies are needed to demonstrate that whether melatonin and MeJA interact with each other to induce antioxidant activity during plant response to cold stress.

\section{ABA Plays a Vital Role in the Rootstock- Induced Increase of the Antioxidant Potential and Cold Tolerance}

Numerous studies have proven that ABA is critical in regulating plant tolerance to various stresses such as cold, heat, drought, and salt (Bulgakov et al., 2019). Root-originated ABA as a long-distance signal plays a crucial role in root-to-shoot communication that regulates plant responses to abiotic stresses ( $\mathrm{Li}$ et al., 2018). Here, we found that pumpkin rootstocks promote the accumulation of ABA in watermelon leaves after cold exposure (Figure 3). Furthermore, pretreatment with ABA enhanced the antioxidant potential and alleviated cold-induced oxidative stress in $\mathrm{Cl}$ plants, while pretreatment with fluridone, an ABA synthesis inhibitor, abolished the pumpkin rootstock-induced increase of the antioxidant potential and cold tolerance (Figures 6, 7). These findings indicate that ABA is involved in pumpkin rootstockinduced tolerance to cold and increased antioxidant potential. The ABA content in xylem sap increased in response to cold stress in $\mathrm{Cl}$ and especially $\mathrm{Cm}$ plants; however, the rate of ABA exudation reduced (Supplementary Figure S1). This was associated with the decreased sap exudation rate by cold-caused inhibition of root vitality. Notably, the increase of ABA accumulation in $\mathrm{Cm}$ leaves was accompanied by significant increases in the transcript levels of NCED6 in leaves, $\mathrm{ABA}$ contents in rootstocks, and higher exudation rates of ABA after exposure to cold stress (Figure 3). Therefore, these results suggest that pumpkin rootstock-originated $\mathrm{ABA}$ may act as a root-to-shoot signal that partly contributes to the ABA accumulation and consequent cold tolerance of watermelon shoots.

\section{Interaction Between ABA and Melatonin or Meja in the Rootstock-Induced Increase of the Antioxidant Potential and Cold Tolerance}

As two crucial plant growth regulators, the interaction between ABA and melatonin in regulating multiple physiological processes, such as seed germination, stomatal movement, biosynthesis of cuticular waxes, and defense against various abiotic stresses, has been well-documented (Li et al., 2015, 2019, 2020, 2021a,b). However, the mutual effects of ABA and melatonin under stress are still controversial. For instance, exogenous application of melatonin was shown to increase the accumulation of ABA in Elymus nutans and cucumber under cold stress (Fu et al., 2017; Zhao et al., 2017). However, melatonin attenuated ABA accumulation by inhibiting the expression of ABA biosynthesis genes under drought and salt stress (Li et al., 2015; Hu et al., 2021). Similarly, melatonininduced suppression of heat-induced leaf senescence could be associated with inhibiting ABA synthesis and signaling in tomato and perennial ryegrass (Zhang et al., 2017; Jahan et al., 2021). Pretreatment with ABA significantly increased melatonin accumulation under salt stress (Hu et al., 2021), whereas exogenous $\mathrm{ABA}$ had almost no effect on melatonin accumulation in Elymus nutans response to cold stress (Fu et al., 2017). Therefore, the mutual effects of ABA and melatonin are different in plant responses to different stresses. Here, our results showed that foliar application of ABA and melatonin induces their mutual accumulation, as well as the transcript levels of COMT1 and NCED6, respectively, in the leaves of $\mathrm{Cl}$ plants after cold exposure (Figures 4A, 8A). Moreover, pretreatment with fluridone and CPA prevented the pumpkin rootstock-induced accumulation of melatonin and ABA, respectively (Figures 4B, 8B). Furthermore, CPA pretreatment abolished the ABA-induced increase of the antioxidant potential and cold tolerance in $\mathrm{Cl}$ plants (Figures 6A, 7A). These data indicate that ABA and melatonin positively interact with each other to enhance the antioxidant potential and cold tolerance. 
$\mathrm{ABA}$ and JA function together to regulate plant defense against multiple biotic or abiotic stresses (Moons et al., 1997; Anderson et al., 2004; Adie et al., 2007). ABA is essential for the biosynthesis of JAs, which act downstream of ABA to induce the activation of the C-REPEAT BINDING FACTOR pathway and cold tolerance in tomato (Wang et al., 2016). Our results show that, like melatonin, MeJA functions together with $\mathrm{ABA}$ to enhance the cold tolerance of grafted watermelon plants. This conclusion is supported by our findings that (1) exogenous $\mathrm{ABA}$ and MeJA application increased their mutual accumulation in $\mathrm{Cl}$ leaves after cold exposure by upregulating the relative expression of $A O C 1$ and NCED6, respectively (Figures 5A, 8A); (2) pretreatment with fluridone or DIECA prevented pumpkin rootstock-induced melatonin or ABA accumulation, respectively (Figures 5B, 8B); and (3) DIECA pretreatment prevented the ABA-induced increase of the antioxidant potential and cold tolerance in $\mathrm{Cl}$ plants (Figures 6A, 7A).

\section{CONCLUSION}

In summary, we have revealed in this study that $A B A$ as a potential root-to-shoot signal plays an important role in the rootstock-enhanced cold tolerance of watermelon plants. The rootstock-mediated $\mathrm{ABA}$ accumulation in leaves promotes the accumulation of melatonin and MeJA, which in turn induces the accumulation of $\mathrm{ABA}$, forming a positive self-amplifying feedback loop. Melatonin and MeJA increase the antioxidant potential and subsequently alleviate cold-induced oxidative damage. However, it remains elusive how ABA, melatonin, and MeJA interact with each other in grafted plants in response to cold stress.

\section{REFERENCES}

Adie, B. A., Pérez-Pérez, J., Pérez-Pérez, M. M., Godoy, M., Sánchez-Serrano, J. J., Schmelz, E. A., et al. (2007). ABA is an essential signal for plant resistance to pathogens affecting JA biosynthesis and the activation of defenses in Arabidopsis. Plant Cell 19, 1665-1681. doi: 10.1105/tpc.106.048041

Ali, M. S., and Baek, K. H. (2020). Jasmonic acid signaling pathway in response to abiotic stresses in plants. Int. J. Mol. Sci. 21:621. doi: 10.3390/ ijms 21020621

Anderson, J. P., Badruzsaufari, E., Schenk, P. M., Manners, J. M., Desmond, O. J., Ehlert, C., et al. (2004). Antagonistic interaction between abscisic acid and jasmonate-ethylene signaling pathways modulates defense gene expression and disease resistance in Arabidopsis. Plant Cell 16, 3460-3479. doi: 10.1105/ tpc.104.025833

Arnao, M. B., and Hernández-Ruiz, J. (2014). Melatonin: plant growth regulator and/or biostimulator during stress? Trends Plant Sci. 19, 789-797. doi: 10.1016/j.tplants.2014.07.006

Bose, J., Rodrigo-Moreno, A., and Shabala, S. (2014). ROS homeostasis in halophytes in the context of salinity stress tolerance. J. Exp. Bot. 65, 1241-1257. doi: $10.1093 / \mathrm{jxb} / \mathrm{ert} 430$

Bulgakov, V. P., Wu, H. C., and Jinn, T. L. (2019). Coordination of ABA and chaperone signaling in plant stress responses. Trends Plant Sci. 24, 636-651. doi: $10.1016 /$ j.tplants.2019.04.004

Cakmak, I., and Marschner, H. (1992). Magnesium deficiency and high light intensity enhance activities of superoxide dismutase, ascorbate peroxidase,

\section{DATA AVAILABILITY STATEMENT}

The datasets presented in this study can be found in online repositories. The names of the repository/repositories and accession number(s) can be found in the article/ Supplementary Material.

\section{AUTHOR CONTRIBUTIONS}

HL: conceptualization, project administration, and writing-review and editing. YG and HL: data curation, formal analysis, and writing-original draft. XZ and HL: funding acquisition. YG, JY, ZS, JC, and CW: investigation. JY, YZ, JM, and XZ: resources. $\mathrm{XZ}$ : supervision. All authors have read and agreed to the published version of the manuscript.

\section{FUNDING}

This research was funded by the National Key Research and Development Program of China, grant number 2018YFD1000800; the National Natural Science Foundation of China, grant numbers 31801884 and 31972479; the China Agriculture Research System of MOF and MARA, grant number CARS-25; and the Tang Scholar of Northwest A\&F University.

\section{SUPPLEMENTARY MATERIAL}

The Supplementary Material for this article can be found online at: https://www.frontiersin.org/articles/10.3389/fpls.2021.785317/ full\#supplementary-material

and glutathione reductase in bean leaves. Plant Physiol. 98, 1222-1227. doi: 10.1104/pp.98.4.1222

Chinnusamy, V., Zhu, J., and Zhu, J. K. (2007). Cold stress regulation of gene expression in plants. Trends Plant Sci. 12, 444-451. doi: 10.1016/j. tplants.2007.07.002

Danquah, A., Zelicourt, A. D., Colcombet, J., and Hirt, H. (2014). The role of ABA and MAPK signaling pathways in plant abiotic stress responses. Biotechnol. Adv. 32, 40-52. doi: 10.1016/j.biotechadv.2013.09.006

Dat, J., Vandenabeele, S., Vranová, E., Van Montagu, M., Inzé, D., and Van Breusegem, F. (2000). Dual action of the active oxygen species during plant stress responses. Cell. Mol. Life Sci. 57, 779-795. doi: 10.1007/ s000180050041

Davis, A. R., Perkins Veazie, P. M., Sakata, Y., Lopez-Galarza, S., Maroto, J. V., Lee, S., et al. (2008). Cucurbit grafting. Criti. Rev. Plant Sci. 27, 50-74. doi: $10.1080 / 07352680802053940$

Elstner, E. F., and Heupel, A. (1976). Inhibition of nitrite formation from hydroxylammoniumchloride: a simple assay for superoxide dismutase. Anal. Biochem. 70, 616-620. doi: 10.1016/0003-2697(76)90488-7

Fu, J., Wu, Y., Miao, Y., Xu, Y., Zhao, E., Wang, J., et al. (2017). Improved cold tolerance in Elymus nutans by exogenous application of melatonin may involve ABA-dependent and ABA-independent pathways. Sci. Rep. 7:39865. doi: 10.1038/srep39865

Hodges, D. M., DeLong, J. M., Forney, C. F., and Prange, R. K. (1999). Improving the thiobarbituric acid-reactive-substances assay for estimating lipid peroxidation in plant tissues containing anthocyanin and other interfering compounds. Planta 207, 604-611. doi: 10.1007/s004250050524 
Hu, E. M., Liu, M., Zhou, R., Jiang, F. L., Sun, M. T., Wen, J. Q., et al. (2021). Relationship between melatonin and abscisic acid in response to salt stress of tomato. Sci. Hortic. 285:110176. doi: 10.1016/j.scienta. 2021.110176

Hu, X. Y., Neill, S., Cai, W. M., and Tang, Z. C. (2003). Hydrogen peroxide and jasmonic acid mediate oligogalacturonic acid-induced saponin accumulation in suspension-cultured cells of panax ginseng. Physiol. Plantarum. 118, 414-421. doi: 10.1034/j.1399-3054.2003.00124.x

Jahan, M. S., Shu, S., Wang, Y., Hasan, M. M., and Guo, S. (2021). Melatonin pretreatment confers heat tolerance and repression of heat-induced senescence in tomato through the modulation of ABA- and GA-mediated pathways. Front. Plant Sci. 12:650955. doi: 10.3389/fpls.2021.650955

Kazan, K. (2015). Diverse roles of jasmonates and ethylene in abiotic stress tolerance. Trends Plant Sci. 20, 219-229. doi: 10.1016/j.tplants.2015. 02.001

Li, H., Chang, J. J., Zheng, J. X., Dong, Y. C., Liu, Q. Y., Yang, X. Z., et al. (2017). Local melatonin application induces cold tolerance in distant organs of Citrullus lanatus L. via long distance transport. Sci. Rep. 7:40858. doi: $10.1038 /$ srep40858

Li, H., Guo, Y. L., Cui, Q., Zhang, Z. X., Yan, X., Ahammed, G. J., et al. (2020). Alkanes (C29 and C31)-mediated intracuticular wax accumulation contributes to melatonin- and ABA-induced drought tolerance in watermelon. J. Plant Growth Regul. 39, 1441-1450. doi: 10.1007/ s00344-020-10099-z

Li, H., Guo, Y. L., Lan, Z. X., Xu, K., Chang, J. J., Ahammed, G. J., et al. (2021a). Methyl jasmonate mediates melatonin-induced cold tolerance of grafted watermelon plants. Hortic. Res. 8:57. doi: 10.1038/s41438-02100496-0

Li, H., Guo, Y., Lan, Z. X., Zhang, Z. X., Ahammed, G. J., Chang, J., et al. (2021b). Melatonin antagonizes ABA action to promote seed germination by regulating $\mathrm{Ca}^{2+}$ efflux and $\mathrm{H}_{2} \mathrm{O}_{2}$ accumulation. Plant Sci. 303:110761. doi: $10.1016 /$ j.plantsci.2020.110761

Li, H., Liu, S. S., Yi, C. Y., Wang, F., Zhou, J., Xia, X. J., et al. (2014a). Hydrogen peroxide mediates abscisic acid-induced HSP70 accumulation and heat tolerance in grafted cucumber plants. Plant Cell Environ. 37, 2768-2780. doi: $10.1111 /$ pce. 12360

Li, H., Mo, Y. L., Cui, Q., Yang, X. Z., Guo, Y. L., Wei, C. H., et al. (2019). Transcriptomic and physiological analyses reveal drought adaptation strategies in drought-tolerant and -susceptible watermelon genotypes. Plant Sci. 278, 32-43. doi: $10.1016 /$ j.plantsci.2018.10.016

Li, W., Ollas, C. D., and Dodd, I. C. (2018). Long-distance ABA transport can mediate distal tissue responses by affecting local ABA concentrations. J. Integr. Plant Biol. 60, 16-33. doi: 10.1111/jipb.12605

Li, H., Wang, F., Chen, X. J., Shi, K., Xia, X. J., Considine, M. J., et al. (2014b). The sub/supra-optimal temperature-induced inhibition of photosynthesis and oxidative damage in cucumber leaves are alleviated by grafting onto figleaf gourd/luffa rootstocks. Physiol. Plantarum. 152, 571-584. doi: $10.1111 / \mathrm{ppl} .12200$

Li, H., Wang, Y., Wang, Z., Guo, X., Wang, F., Xia, X. J., et al. (2016). Microarray and genetic analysis reveals that csa-miR159b plays a critical role in abscisic acid-mediated heat tolerance in grafted cucumber plants. Plant Cell Environ. 39, 1790-1804. doi: 10.1111/pce.12745

Li, C., Xian, T. D., Liang, D., Cong, C., Jia, D. F., and Ma, F. W. (2015). Melatonin mediates the regulation of ABA metabolism, free-radical scavenging, and stomatal behaviour in two malus species under drought stress. J. Exp. Bot. 66, 669-680. doi: 10.1093/jxb/eru476

Livak, K. J., and Schmittgen, T. D. (2001). Analysis of relative gene expression data using real-time quantitative PCR and the $2^{-\triangle \Delta C T}$ method. Methods 25, 402-408. doi: 10.1006/meth.2001.1262

Moons, A., Prinsen, E., Bauw, G., and Van Montagu, M. (1997). Antagonistic effects of abscisic acid and jasmonates on salt stress-inducible transcripts in rice roots. Plant Cell 9, 2243-2259. doi: 10.1105/tpc.9. 12.2243

Ntatsi, G., Savvasa, D., Druegec, U., and Schwarzb, D. (2013). Contribution of phytohormones in alleviating the impact of sub-optimal temperature stress on grafted tomato. Sci. Hortic. 149, 28-38. doi: 10.1016/j. scienta.2012.09.002

Pan, X., Welti, R., and Wang, X. M. (2010). Quantitative analysis of major plant hormones in crude plant extracts by high-performance liquid chromatography-mass spectrometry. Nat. Protoc. 5, 986-992. doi: 10.1038/ nprot. 2010.37

Pape, C., and Lüning, K. (2006). Quantification of melatonin in phototrophic organisms. J. Pineal Res. 41, 157-165. doi: 10.1111/j.1600-079X.2006. 00348.x

Park, W. J. (2011). Melatonin as an endogenous plant regulatory signal: debates and perspectives. J. Plant Biol. 54, 143-149. doi: 10.1007/ s12374-011-9159-6

Patra, H. K., Kar, M., and Mishra, D. (1978). Catalase activity in leaves and cotyledons during plant development and senescence. Biochem. Physiol. Pflanzen. 172, 385-390. doi: 10.1016/S0015-3796(17)30412-2

Pratiwi, P., Tanaka, G., Takahashi, T., Xie, X. N., Yoneyama, K., Matsuura, H., et al. (2017). Identification of jasmonic acid and jasmonoyl-isoleucine, and characterization of AOS, AOC, OPR and JAR1 in the model lycophyte Selaginella moellendorffii. Plant Cell Physiol. 58, 789-801. doi: 10.1093/pcp/ pcx031

Rivero, R. M., Ruiz, J. M., Garcia, P. C., López-Lefebre, L. R., Sánchez, E., and Romero, L. (2001). Resistance to cold and heat stress: accumulation of phenolic compounds in tomato and watermelon plants. Plant Sci. 160, 315-321. doi: 10.1016/S0168-9452(00)00395-2

Schachtman, D. P., and Goodger, J. (2008). Chemical root to shoot signaling under drought. Trends Plant Sci. 13, 281-287. doi: 10.1016/j. tplants.2008.04.003

Stewart, R. R. C., and Bewley, J. D. (1980). Lipid peroxidation associated with accelerated aging of soybean axes. Plant Physiol. 65, 245-248. doi: 10.1104/ pp.65.2.245

Wang, F., Guo, Z. X., Li, H. Z., Wang, M. M., Onac, E. G., Zhou, J., et al. (2016). Phytochrome A and B function antagonistically to regulate cold tolerance via abscisic acid-dependent jasmonate signaling. Plant Physiol. 170, 459-471. doi: 10.1104/pp.15.01171

Wang, G. T., Hu, C. Y., Zhou, J., Liu, Y., Cai, J. X., Pan, C. Z., et al. (2019). Systemic root-shoot signaling drives jasmonate-based root defense against nematodes. Curr. Biol. 29, 3430-3438. doi: 10.1016/j.cub.2019.08.049

Wasilewska, A., Vlad, F., Sirichandra, C., Redko, Y., Jammes, F., Valon, C., et al. (2008). An update on abscisic acid signaling in plants and more. Mol. Plant 1, 198-217. doi: 10.1093/mp/ssm022

Wen, D., Gong, B., Sun, S., Liu, S., Wang, X., Wei, M., et al. (2016). Promoting roles of melatonin in adventitious root development of Solanum lycopersicum L. by regulating auxin and nitric oxide signaling. Front. Plant Sci. 7:925. doi: $10.3389 /$ fpls.2016.00718

Willekens, H., Chamnongpol, S., Davey, M., Schraudner, M., Langebartels, C., Van Montagu, M., et al. (1997). Catalase is a sink for $\mathrm{H}_{2} \mathrm{O}_{2}$ and is indispensable for stress defence in $\mathrm{C}_{3}$ plants. EMBO J. 16, 4806-4816. doi: 10.1093/ emboj/16.16.4806

Yang, J., Zhang, J., Wang, Z., Zhu, Q., and Wang, W. (2001). Hormonal changes in the grains of rice subjected to water stress during grain filling. Plant Physiol. 127, 315-323. doi: 10.1104/pp.127.1.315

Yoshida, T., Fernie, A. R., Shinozaki, K., and Takahashi, F. (2021). Longdistance stress and developmental signals associated with abscisic acid signaling in environmental responses. Plant J. 105, 477-488. doi: 10.1111/ tpj.15101

Zhang, J., Shi, Y., Zhang, X. H., Du, H. M., Xu, B., and Huang, B. R. (2017). Melatonin suppression of heat-induced leaf senescence involves changes in abscisic acid and cytokinin biosynthesis and signaling pathways in perennial ryegrass (Lolium perenne L.). environ. Exp. bot. 138, 36-45. doi: 10.1016/j. envexpbot.2017.02.012

Zhang, N., Sun, Q. Q., Zhang, H. J., Cao, Y. Y., Weeda, S., Ren, S. X., et al. (2015). Roles of melatonin in abiotic stress resistance in plants. J. Exp. Bot. 66, 647-656. doi: 10.1093/jxb/eru336

Zhang, H. M., and Zhang, Y. Q. (2014). Melatonin: a well-documented antioxidant with conditional pro-oxidant actions. J. Pineal Res. 57, 131-146. doi: 10.1111/ jpi.12162

Zhao, H. L., Zhang, K., Zhou, X. T., Xi, L. J., Wang, Y. P., Xu, H. J., et al. (2017). Melatonin alleviates chilling stress in cucumber seedlings by up-regulation of CsZat 12 and modulation of polyamine and abscisic acid metabolism. Sci. Rep. 7:4998. doi: 10.1038/ s41598-017-05267-3

Zhou, W. J., and Leul, M. (1998). Uniconazole-induced alleviation of freezing injury in relation to changes in hormonal balance, enzyme activities and 
lipid peroxidation in winter rape. J. Plant Growth Regul. 26, 4-47. doi: 10.1023/A:1006004921265

Conflict of Interest: The authors declare that the research was conducted in the absence of any commercial or financial relationships that could be construed as a potential conflict of interest.

Publisher's Note: All claims expressed in this article are solely those of the authors and do not necessarily represent those of their affiliated organizations, or those of the publisher, the editors and the reviewers. Any product that may be evaluated in this article, or claim that may be made by its manufacturer, is not guaranteed or endorsed by the publisher.

Copyright (๑) 2021 Guo, Yan, Su, Chang, Yang, Wei, Zhang, Ma, Zhang and Li. This is an open-access article distributed under the terms of the Creative Commons Attribution License (CC BY). The use, distribution or reproduction in other forums is permitted, provided the original author(s) and the copyright owner(s) are credited and that the original publication in this journal is cited, in accordance with accepted academic practice. No use, distribution or reproduction is permitted which does not comply with these terms. 